\title{
ESTUDOS GEOFÍSICOS DE UM PLÁCER ANTIGO NA ILHA DE ITAPARICA, BAHIA
}

\author{
Joaquim Xavier Cerqueira Neto \\ PPG/UFBA - Instituto de Geociências, Campus Universitário da Federação, Salvador-Bahia, Brasil - 40.000 \\ Ronald David Barker \\ Departament of Geological Sciences, University of Birmingham P.o. Box 363 - Birmingham B15 2TT, Inglaterra.
}

\begin{abstract}
The investigation of an ancient beach placer on the island of Itaparica, Bahia, through comparison of geophvsical da. ta with mineralogical and sedimentological parameters, gives useful information for the study of similar occurrences, and permits to determine the most efficient geophysical methods for the location of such placers.
\end{abstract}

The results show that: (i) the scintillometer survey is very efficient in the localization and delineation of these occurrences; (ii) the I.P. method may be useful in the investigation of deeply burried deposits, and (iii) the magnetic method does not give reliable results in spite of the large quantity of magnetic minerals (ilmenite) in the deposit.

Measurements by gamma-ray spectrometer on the samples in the laboratory indicate $160 \pm 34 \mathrm{ppm}$ of thorium $10 \pm 2 \mathrm{ppm}$ of uranium $(95 \%$ confidence limits) and a thorium/uranium ratio of $16 \pm 2$ in the placer deposit. The se- dimentological study of samples of the deposit shows the detrital nature of the sediments and indicates a predominance of the following minerals: ilmenite, monazite, zircon and rutile.

It is recommended that extensive and systematic exploration of coastal areas be carried out, especially in the State of Bahia. The use of aerial photographs and an understanding of the Geological Nature of the placers will greatly help in the planning of an efficient and relatively cheap exploration program.

\section{INTRODUÇÃo}

Os pláceres de praia estão entre os mais importantes do ponto de vista econômico (Kreiter, 1968; Maciel e Cruz, 1973), encontrando-se neles, frequientemente, minerais como ilmenita, monazita, zirconita e rutilo, todos com aplicaçoes industriais. A ilmenita é a matéria-prima para a produção do dióxido de titânio, empregado, em larga escala, na indústria de tintas e, em menor quantidade, na indústria aeronáutica, em forma de ligas metálicas. Do concentrado de monazita são obtidos os óxidos e sais de terras raras, como produtos principais, tendo aplicaçăo na indústria eletrônica, na ótica de precisão, na metalurgia e na indústria química; como subproduto, é obtido o bxido de tório. Ainda, do aproveitamento da monazita tem o rejeito radioativo, isto é, resíduos de tório e de urânio (uranato de sodio), com possibilidade de aplicação futura, como combustível nu* clear (Maciel e Cruz, 1973). A zirconita encontra grande aplicaçåo na industria cerâmica. fundição, siderurgia, indús- tria de vidro e polimentos de lentes, e na indústria de papel. O metal zircônio, também obtido da zirconita, tem excelentes propriedades para uso em ligas metálicas, abrasivos e na engenharia nuclear. A zirconita é considerada o mineral do século (Kreiter, 1968), e toda a sua potencialidade industrial ainda não esía sendo aproveitada no nosso país. O rutilo tem a sua principal aplicacão nos eletrodos para solda elétrica.

Portanto, a prospecção desses minerais é de grande importância e, por isto, tem recebido uma atenção maior dos diferentes órgãos de pesquisa como CNPq , CNEN, DNPM , CPRM (Maciel e Cruz, 1973), e inclusive, do Programa de Pesquisa e Pós-Graduação em Geo-física da Universidade Federal da Bahia que se empenha, também, no estudo dos depósitos pláceres. $\overline{\mathrm{E}}$ oportuno ressaltar a importância dos minerais pesados desses depósitos como método relevante e de crescente interesse no campo da estratigrafia, da sedimentologia, tectônica, etc. (Parfenoff, Pome- rol e Toureng, 1970). Assim, foi estudado, detalhadamente, um plácer de praia antigo situado na llha de Itaparica, a $21 \mathrm{~km}$ de distância do terminal de Bom Despacho e localizado na Fazenda Pedrão, entre a Ponta da Cruz e a Ponta de Aratuba (Fig. 1). A investigação deste tipo de depósito se limita, normalmente, aos estudos sedimentológicos e de análises mineralógicas.

Porém, no presente trabalho, além desses estudos, também foram empregados métodos de prospecção geofísica, visando obter informações proveitosas no estudo de novas ocorrências, bem como testar os métodos geofísicos mais eficientes na prospeç̧ão sistemática e estudo deste tipo de depósito. Procurou-se, então, estabelecer correlações das respostas dos métodos geofísicos com parâmetros mineralógicos e sedimentológicos típicos do depósito plácer. Com estes dados foi, ainda, calculada a reserva de minerais úteis da jazida. 


\section{GEOLOGIA DO DEPÓSITO}

A área estudada se encontra quase loda coberta por sedimentos quaternários. Na parte leste e ao longo da praia, ocorrem afloramentos de um arenito pouco consolidado, laminação parale la, granulação média a fina e cor esver deada, possivelmente da Formação Marfim (Viana et alii, 1971; Fonseca, Wall e Maia, 1962). Os cortes na rodovia que atravessa a área estudada expuseram arenitos friáveis, intercalados com folhelhos pretos da Fm. Alagoas.

Do ponto de vista geomórgico, a área é uma restinga, observando-se vestígios de antigas falésias nas duas elevações vizinhas. Verifica-se, também, um alinhamento topográfico (elevado de 6 $\mathrm{m}$, em relação ao nível do mar), paralelo à linha de praia e disposto normal mente a um paleovale. $O$ depósito caracteriza-se, perfeitamente, como um antigo plácer de praia. (Fig. 1)

\section{MÉTODOS GEOFÍSICOS EMPREGADOS}

Cintilometria - A cintilometria foi usada no reconhecimento e na delimitação superficial do depósito. Empregou-se um cintilômetro modelo SPP-3 Saphymo Srat, portátil. Na área do plácer foram feitos perfís transversais (indicados por letras maiúsculas nas figuras), anotando-se as leituras onde ocorriam picos (altos e baixos), e nas estaç̋es afastadas $50 \mathrm{~m}$. Este procedimento de campo, anotando-se os valores picos encontrados na área, é muito importante nos levantamentos radiométricos, porque possibilita a confecção de mapas de iso-intensidades mais precisos do que aqueles realizados com valores medidos somente nas estações, sem o registro desses picos, muito comuns nas anomalias radioativas. O mapa de iso-intensidades de radiações gama está representado na Figura 2. Observa-se que dentro deo contorno da anomalia existem contagens elevadas, evidenciando grandes concentrações de minerais radiotaivos. Paricularmente notáveis são os valores altos registrados na extremidade oeste, ao lado da rodovia. Esta anomalia se encontra em ambiente de brejo com sedimentos argilo-arenosos escuros. Uma explicação possível para estes elevados valores de radiação é ter havido, por exemplo, a lixiviação do urânio nas partes vizinhas, mais altas, e alí se depositado, uma vez que o urânio pode ser absorvido pela argila, matéria orgânica, ou outros materiais finalmente divididos (McKelvey e Nelson, 1950). (Fig. 2)
Espectometria gama - O método foi empregadi nus esiudos de laboratório cum " ubjetivo de determinar os teores de urânio, tório e potássio. Os resultados desse método de análise são válidos, apenas, se a série radioativa estiver em equilíbrio secular. Assim, a medida de qualquer um dos elementos da família conduz à determinação, indirela, dos progenitores, como U235, U238 e Th232. E importante lembrar que a deteç̧ão de radioatividade, pura e simplesmente, não implica necessariamente, na existência desses elementos. Mero (1960) cita exemplos históricos de empresas norte-americanas que lavraram jazidas de materiais radioativos e não encontraram o urânio lão almejado. Cerqueira Neto (1976) efetuou a análise de equilíbrio de algumas amostras de material do depósito plácer de Itaparica, mostrando que, pelo menos, o tório esiá em equilíbrio secular. As amostras foram coletadas em três niveis diferentes (na superfície, a um e a dois metros de profundidade), sobre uma malha regular $50 \mathrm{~m} \times 50 \mathrm{~m}$, sendo analisados cerca de $380 \mathrm{~kg}$ de sedimentos.

$O$ espectrômetro utilizado é constituído de um detector de cristal de NaI (TL), acoplado a uma unidade analisadora multicanal Hewllett Packard. Também, foi utilizado um espectrômetro com detector de germânio-lítio com alta resolução $(4 \%)$ na idenlificação dos emissores gama. A idenlificação do urânio e do tório foi feita mediante a comparação dos espectrosgama dos padrões de urânio $\star$ e tório com os espectros obtidos do material a ser analisado. (Fig. 3).

Análise dos resultados - Os teores de urânio, tório e potássio encontram-se na Tabela 1. A maior incerteza associada aos teores de urânio é cerca de $30 \%$, exceto para os teores muito baixos, quando será maior, especialmente, se a amostra for rica em tório. No caso do tório a incerteza está em torno de $10 \%$ (Fig. 4). Para o potássio a precisão da medida, de um modo geral, conduz a dois algarismo significativos. Todavia, quando as amostras são muito ricas em $\mathrm{Th}$ e $\mathrm{U}$ a incerteza quanto ao teor de potássio é plena, em virtude da contribuição de interação Compton. Por exemplo, vê-se na Tab. 1 que em algumas amosiras como $\mathrm{A} 0 / 0$ E $3 / 2, S 2 / 2$ e $S 5 / 2$, ricas em $U$ e $T h$, não foi possível a deteção do potássio (Fig. 4).

Os teores de tório, na profundidade de $2.00 \mathrm{~m}$, se encontram na Fig. 5, em forma de curvas de isoteores, mostrando o aspecto do depósito em profundidade. Observe-se a feição alongada, já evidenciada pela cintilometria. A
Tabela 2 mostra os parâmetros estatísticos para os três elementos e os limites de confiança de $95 \%$, excluindo-se o erro experimental. (Fig. 5)

Segundo Bell (1957), as concentrações máximas de urânio e tório em pláceres de praia chegam a 70 ppm e 3.000 $\mathrm{ppm}$, respectivamente, indicando os leores 2 ppm e 60 ppm como médias prováveis. Porém, no plácer de Itaparica observaram-se máximos de $45 \mathrm{ppm}$ de urânio e 1.300 ppm de tório, e teores médios bem maiores: $160+34$ e $10+2$ ppm de tório e urânio, respectivamente, nos limites de $95 \%$ de confiança. (vide as tabelas $1 \mathrm{e} 2$ ).

Polarização Elétrica Induzida - Este método tem o seu emprego consagrado na prospecção de sulfetos disseminados. Mas a sua utilização é bem mais ampla, por ser sensível à deteç̧ão de minerais metálicos condutores disseminados, (Seigel, 1967), além de permitir uma visualização qualitativa dos diferentes parâmetros em profundidade. Isto, possibilita a delimitação de corpos mineralizados e, portanto, melhor orienta os trabalhos de sondagens mecânicas. $O$ método, também, é muito útil na investigação de água subterrânea.

Um perfil foi realizado ao longo da transversal "D" (Fig. 2) de modo a interceptar a anomalia perpendicu* larmente. $O$ instrumento utilizado, modelo P650, da Mc Phar, mede, diretamente, o efeito de freqüência (EPF) e a resistividade aparente dados, respectivamente, por:

$$
\begin{gathered}
\mathrm{EPF}=\frac{P_{\mathrm{ca}}-P_{\mathrm{cd}}}{P_{\mathrm{ca}}} 10^{2} \\
P_{\mathrm{a}}=\sqrt{P_{\mathrm{ca}} P_{\mathrm{cd}}}
\end{gathered}
$$

onde, $p$ ca $=$ resistividade aprente, relativa a freqüencia de campo elétrico $(5,0 \mathrm{cps})$ e $P \mathrm{~cd}=$ resistividade aparente, relativa à freqüência de referência do nível "cd" $(0,3125 \mathrm{cps})$.

De (1) e (2) é derivado um terceiro parâmetro, o fator metálico aparente, dado por:

$$
\mathrm{FM}_{\mathrm{a}}=\frac{\mathrm{EPF}}{\mathrm{P}_{\mathrm{a}}} \quad 2 \pi 10^{2}
$$

que tem a dimensão de condutividade e fornece uma medida de quantidade de condução. Adotou-se o arranjo dipolodipolo com o afastamento de $3,00 \mathrm{~m}$ entre os elétrodos de cada dipolo, variando de $\mathrm{n}=1$ a $\mathrm{n}=5$.

Análise dos resultados - As variações da resistividade aparente, do efeito de freqüência e do fator metálico no perfil estão na Fig. 6. 
Observe que a resistividade aparente, de um modo geral, cresce no sentido $\mathrm{N}$-S, variando entre $20 \mathrm{~m}$ no lado da praia. Esta variação reflete a presença de material argiloso subjacente, e/ou do lençol freático, mais superficial, no trecho à esquerda da estação $\mathrm{D} / 2$; parece que não tem qualquer relação com a mineralização. Já a anomalia de polarização induzida ressalta bem a zona de maior concentração dos mine. rais pesados. Entre as estações $D / 1$ e $\mathrm{D} / 2$, os valores do EPF são fortemente afetados pelo ruído de polarização de membrana devido z̀ argila. Os maiores valores do EPF, não afetados pelo ruído, situam-se entre as estações $\mathrm{D} / 2$ e $D / 3$, O perfil do fator metálico mostra a faixa de ocorrência mineral, evidenciando bem o valor do "background", situado à direita do perfil.

Magnetometria - $\mathrm{O}$ emprego do método magnético é muito útil em áreas de ocorrências de minerais magnéticos. $E$, em geral, a magnetita está entre os minerais que têm a presença mais constante nos depósitos detríticos, podendo mesmo constituir a maior parte da fração pesada (Parfenoff, 1970). Assim, o emprego do método visou registrar os efeitos de possíveis minerais magnéticos existentes no depósito. No levantamento magnetométrico empregou-se um magnetômetro de precessão nuclear, modelo MPN 100, fazendo-se leituras em todas as estações definidas pela malha regular $50 \mathrm{~m} \times 50 \mathrm{~m}$, compatível com o grau de detalhe desejado.

Os dados do levantamento magnetométrico estão na Fig. 7.

Observa-se que as variações relativas da intensidade do campo são muito pequenas e apresentam um padrão puco sugestivo pra a interpretação. A feição apresentada no mapa de contorno não concorda com a forma do depósito evidenciada, por exemplo, pela cintilometria (Fig. 2). Provavelmente, estas variações registradas são devidas à componente regional. Apesar da boa precisão do levantamento ( $t$ - 3 gamas) não se registraram anomalias magnéticas. Os resultados obtidos sugerem, por tanto, que o método não é muito útil na exploração de depósitos minerais pesados nesta região.

\section{ANÁLISE SEDIMENTOLÓGICA}

Esta análise compreendeu: a determinação dos teores de minerais pesados, as suas distribuições espacial e de freqüências, identificação das diferentes espécies minerais, deter- minação quantitativa dos minerais como ilmenita, monazita e zirconita; e a granulometria do sedimento.

A metodologia adotada no estudo dos minerais pesados está esquematizada na Figura 8, e fundamenta-se nos métodos de análises descritos pro Parfenoff (1967), Griffith (1967) e Parfenoffi, Pomerol e Tourenq (1970), padronizados para o estudo desses minerais. (Fig. 8)

A identificação das diferentes espécies minerais foi feita através da microscopia ótica e da difratometria de raios-x. As principais espécies encontradas encontram-se na Tabela 3 . Em algumas amostras o teor de ilmenita atingiu até $70 \%$ da fração de minerais pesados. (Tab. 3)

Distribuições espaciais e de freqüências - Com os teores de minerais pesados (concentrados) foi desenvolvida a análise estatística visando o conhecimento da distribuição e a determinação dos parâmetros estatísticos da população. $\mathrm{Na}$ Figura 9 encontram-se os histogramas mostrando que as distribuições de freqüências dos teores de minerais pesados tem assimetria positiva. Vêem-se, ainda, as curvas de freqüências relativas $e$ acumulativas. $O$ teste da hipótese de que a amostra foi retirada de uma população com distribuição lognormal mostra que esta hipótese não pode ser rejeitada, ao nivel de significância de $5 \%$. Isto é, verifica-se que há um ajustamento das freqüências observadas à distribuição teórica:

$$
\eta\left(L_{1} \mu_{1}, \sigma_{1}\right)=\frac{\exp -\left(L-\mu_{1}\right)^{\left.2 / 2 \sigma^{2}\right)}}{\sigma_{1} \sqrt{2 \pi}}
$$

onde $\mathrm{L}=\log \mathrm{x} ; \mathrm{x}=$ variável aleatória, e as estimativas da média e da variância da população original ( $x$ ) são dadas por:

$$
\begin{gathered}
\mu_{x}=\theta a \mu\left|+a^{2} \sigma_{1}^{2}\right| 2 ; a=\log _{b} \theta \\
S_{x}=U_{x}^{2}\left(\theta \sigma^{2} a^{2}-1\right) ; \theta=2,71828 \ldots
\end{gathered}
$$

sendo $\mu_{\mathrm{e}}$, e $\sigma_{\mathrm{e}}$ respectivamente, a média e o desvio padrão da população com distribuição lognormal. (Fig. 9)

As distribuições espaciais dos minerais pesados estão mostradas nas Figuras 10 e 11 , respectivamente, para as profundidades de um e dois metros, em relação à superfície do terreno.

$$
\text { (Figs. } 10 \text { e 11) }
$$

Análise granulométrica - Na Figura 12, encontram-se algumas distribuições acumulativas, em graficos log-probabilidade, dos diâmetros dos grãos do sedimento, na escala 0 de Krumbein. Isto é, $\boldsymbol{\Phi}=\log _{2} \mathrm{~d}=$ diâmetro em milímetros (Krumbein e Graybill, 1965). (Fig. 12)

A análise estatística dos dados de granulometria é desenvolvida com base nos quatro parâmetros de Folk e Ward (1957), estimadores da tendência central, grau de seleção (dado pelo desvio-padrão gráfico), assimetria gráfica e curtose gráfica. Estes parâmetros são os de uso mais comum na análise de granulometria (Suguio, 1973). Os parâmetros médios amostrais e os seus limites de confiança de $95 \%$ encontram-se na tabela 4 .

Os limites de confiança foram deter. minados por meio da distribuição " $t$ " de Student, para os graus de liberdade $v=\mathrm{N}-1$.

Portanto, com base nestes dados, o sedimento é classificado como um areia média (escala de Wenthworth), moderadamente selecionada, distribuição aproximadamente simétrica e meso. cúrtica; de acordo com as escalas sugeridas por Folk e Ward (1957). A porosidade de sedimentos com este diâmetro médio $(1,75$ unid. $\boldsymbol{\Phi})$ varia entre $41 \%$ e $48 \%$, segundo Pettijohn (1957). Os pontos de truncamentos nas curvas acumulativas de várias amostras situam-se nas faixas estabelecidas por Visher (1969), para sedimentos de praia.

\section{ANÁLISE dE CORRELAÇÃo DOS DADOS}

Correlação tório "versus" minerais pesados - O estudo de correlação entre os teores de tório e os teores de minerais pesados (concentrado) do depósito mostra que existe uma correlação linear. A reta de regressão linear está na Figura 13. $O$ ajustamento dos valores observados a uma parábola do $2^{\circ}$ grau, pelo método dos mínimos quadrados, conduz aos mesmos resul. tados do desvio-padrão e do coeficiente de correlação. Os parâmetros desta curva são: (Fig. 13)

$$
\begin{aligned}
& a=-3,6595 \quad c=-0,0189 \\
& b=11,7848 \quad Y=a+b x+c x^{2}
\end{aligned}
$$

Correlação urânio "verusus" tório . As concentrações de urânio e de tório e a relação $\mathrm{Th} / \mathrm{U}$ segundo Adams e Weaver (1958), são indicadores de processos e ambientes sedimentares. Estes autores sugerem que muitos pláceres e, também, depósitos de bauxita pertencem a um fácies geoquímico com relação $\mathrm{Th} / \mathrm{U}$ superior a 7 , 
apresentando teor de tório próximo ou superior a $50 \mathrm{ppm}$. Em amostras de pláceres de praia da Flórida, Murray e Adams (1958) encontraram teores de urânio e de tório iguais a $74 \pm 1,9$ ppm, e $160 \pm 2,9$ ppm, respectivamente, e $21,1 \pm 0,1$ ppm para a relação Th/U. No plácer de Itaparica a relação urânio-tório encontrada é $\mathrm{Th} / \mathrm{U}=16+2$. Entre as expressões exponenciais, linear e parabólica, pesquisadas através de mínimos quadrados, para 117 graus de liberdade, verificou-se o melhor ajustamento à equação:

$$
Y=a x^{b} ;
$$

onde $\mathrm{a}=0,1903, \mathrm{~b}=0,7934, \mathrm{e}$ coeficiente de correlação, igual a 0,9188 . A distribuição dos pontos se encontra na (Fig. 14)

Minerais pesados "versus" granulometria - Pode-se estabelecer uma correlação entre os minerais pesados do depósito e os sedimentos, em termos do diâmetro médio. Isto é, estes minerais estão ocorrendo num depósito cujos diâmetos médios dos grãos (média geométrica) nas amostras do sedimento estão entre $0,27 \mathrm{~mm}$ e $0,33 \mathrm{~mm}$, 95 vezes em 100 . Verificou-se que o conjunto de pontos, teores de minerais pesados "versus" diâmetro médio, apresenta-se disperso, no gráfico cartesiano.

A correlação dos teores de monazita com os teores de tório dados pela espectrometria gama ficou prejudicada em virtude de ser pequena a amostra de monazita, comparada à amostra dos teores de tório.

\section{RESERVA DE MINERAIS ÚTEIS DO DEPÓSITO}

O cálculo para determinar a quantidade de minerais da jazida foi feito com base nos mapas de isoteores (Figuras 10 e 11), no valor médio do teor de minerais pesados $(13,8 \%$, em peso) e nos teores médios de cada espéie mineral (Tabela 3). Empregou-se a fórmula:

$$
Q=p u_{g}(1-\eta) v_{t} 10^{-2} \mathrm{em} \text { toneladas }
$$

onde:

$\mathrm{p}=$ teor médio de minerais pesados

$\mu_{\mathrm{g}}=$ massa especifico real dos grãos do sedimento $\left(2,67 \mathrm{t} / \mathrm{m}^{3}\right)$

$\eta=$ porosidade $(41 \%)$

$\mathrm{Vt}=$ volume do depósito $\left(\mathrm{m}^{3}\right)$

Note que $\mu_{\mathrm{g}}(1-v)=\mu_{\mathrm{S}}$, é a massa específica apatente do material bruto. $\mathrm{Na}$ Tabela 5 encontram-se os valores das reservas medida e indicada.

\section{CONCLUSÕES}

\section{Utilização e Eficiência dos Métodos Geofísicos}

O estudo mineralógico, mesmo segundo um fluxograma simplificado como o da Fig. 8, é necessariamente demorado, se deseja estudar, criteriosamente, um depósito. Observe-se que, para conhecer o depósito tridimensionalmente, ter-se-ia, em malha regular com " $m$ " transversais e " $n$ " estações, um total de $\mathrm{m} \times \mathrm{n} \times \mathrm{p}$ (onde $\mathrm{p}$ é o número de amostras em cada furo de sondagem) amostras a serem processadas. A utilização dos métodos geofísicos permitem a redução do número de análises mineralógicas que seriam feitas, apenas, em amostras coletadas em posições estratégicas da ocorrência.

\section{a) Radiometria}

A cintilometria foi muito eficiente na localização e delimitação superficial dc depósito, confirmando a utilidade do método na prospecção desses depósitos. Contudo, é possível a coorrência de depósitos soterrados nos quais as radiações gama, atenuadas, não seriam bem detectadas na superfície. Uma cobertura de solo com poucas dezenas de centímetros, já seria suficiente para esta atenuação.

A espectrometria gama de laboratório, além da determinação dos teores de urânio e tório, fornece também o teor de monazita, através da correlação tório vs monazita. Uma vantagem do emprego do método é o fato de serem usadas aproximadamente $1.000 \mathrm{~g}$ do sedimento, de uma única vez, contra menos de $10 \mathrm{~g}$. usadas na análise mineralógica, que, além disso, estaria sujeita às incertezas do processo de redução da amostra. $\hat{\mathrm{E}}$ bem conhecido na estatística, que as menores amostras conduzem a uma maior dispersão dos valores da grandeza medida. Neste trabalho cerca de $380 \mathrm{~kg}$. de amostras foram analisadas pela espectrometria gama.

b) polarização induzida - resistividade

O método pode ser empregado para investigar depósitos pláceres em profundidade. Todavia, reconhece-se a necessidade de mais alguma experiência com o emprego do método em depósito relativamente espessos, onde se tenha que empregar maior afastamento entre os elétrodos. $\mathrm{O}$ emprego do método com a configuração e espaçamento usados nesta experiência é mais demorado do que seria para espaçametos normais.

\section{c) Método magnético}

Este método não forneceu bons resultados, apesar da quantidade de ilmenita no depósito. No entanto, fato de não se registrarem anomalias magnéticas indica a ausência de magnetita, confirmada pela análise mineralógica. Parece que depósitos ilmeníticos sem magnetita são mais importantes do ponto de vista do seu aproveitamento. Os resultados obtidos sugerem que o método não é muito útil na exploração de depósitos de minerais pesados nesta região.

\section{Características do depósito}

A análise sedimentológica mostrou que, de um modo geral, os minerais pesados sofrem transporte. Isto, está evidenciado pelo grau de trabalhamento observado nos grãos.

Considerando, por exemplo, o teor de minerais pesados do depósito, e a porcentagem de ilmenita no concentrado, respectivamente $\pm 1,7$ e 58 +3 por cento (em peso), tem-se $80+$ $12 \mathrm{~kg}$. de ilmenita por tonelada de sedimento. Depósitos pláceres com teores de ilmenita variando entre 50 e $100 \mathrm{~kg} / \mathrm{t}$ são classificados como depósitos ricos e econômicos (Kreiter, 1968 p. 18-19). Além disso, são disponíveis outros minerais como monazita, zirconita e os elementos urânio e tório, cujos teores médios são 10 ppm e 160 ppm respectivamente.

A relação tório-urânio e os teores destes elementos são dados importantes nos estudos desses depósitos, porque podem indicar a quantidade de monazita e/ou zirconita presentes. Certamente, também, serão úteis em estudos petrológicos.

Finalmente, em face da demanda desses minerais, é economicamente justificável um estudo amplo e sistemático de prospecção de novas ocorrências no litoral. $\mathrm{O}$ controle geomorfológico dessas concentrações sugere que o emprego de fotografias aéreas, provavelmente, será valioso no selecionamento de áreas propícias.

\section{AGRADECIMENTOS}

Ao Dr. David Lawrence Thruber, aos professores Shiguemi Fujimori e Garaldo S. Vilas Boas, pela apreciação dos temas mais especializados dentro da sedimentologia e mineralogia. $\bar{A}$ Petrobrás, pela autorização para consultas e mapas e relatórios internos, a Instituto de Geociências da Univer. sidade Federal da Bahia, pelo uso dos seus laboratórios e, finalmente, aos proprietários da Fazenda Pedrão. 


\section{BIBLIOGRAFIA}

ADAMS, J.A.S, and WEAVER, C.E. - 1958 - Thorium to Uranium Ratios as Indicators of Sedimentary Processes: exemple of concept of geochimical facies. Bul. Am Pet., 42: 387-430.

BELL, K.G. - 1957 - Uranium and Thorium in Sedimentary Rocks, in Nuclear Geology p. 98-112. John Wiley \& Sons Inc. Nova lorque.

CERQUEIRA NETO, J.X. - 1976 - Estudo Geofísicos de Pláceres Ilmeniticos e Monaziticos na Ilha de Itaparica, Bahia. Tese de Mestrado. Programa de Pesquisa e Pós Graduação em Geofísica, Universidade Fe deral da Bahia.

FOLK, R.L. and WARD, W.C. - 1957 Brazo River Bar: study in the significance of grain size parameters. Journal of Sedimentary Petrology, 27 (1): 3-21.

FONSECA, J.1. et alii. - 1962 - Mapa Geológico do Recôncavo. Quadrângulo 790m3 1 Rel. 577 SETEX. Petrobrás-RPBA. Salvador-BA.

GRIFFITH, J.C. - 1967 - Scientific Methods in Analysis of Sediments. McGraw-Hil Book Co. Nova lorque.

KOMAROV, V.A. - 1967 - The importance of induced polarizations methods for the exploration of ore deposits, in Min. and Groundwater Geophysics, publ. G.S. Canadá, E.G. Rep. 26: 138-47,

KREITER, V.M - 1968 - Geological Prospecting and Exploration. Mir Publishers, Moscou.

KRUMBEIN, W.C. and Graybill, f.a. - 1965 An Introduction to Statistical Models in Geology. McGraw-tiill Co. Nova lorque.

MACIEL, A.C. e CRUZ, P. - 1973 - Perfil Analítico do Tório e Terras Raras. Ministério das Minas e Energia - DNPM, Bol. 28, Rio de Janeiro.

MACIEL, A.C. e CrUZ, P. - 1973a - Perfil Analítico do Urânio. MME-DNPM, Bol. 27, Rio de Janeiro.

MCKELVEY, V.E. and NELSON, J.M. 1950 - Characteristic of Marine Uraniumbearing Sedimentary Rocks. Economic Geology, 45 (1): 35-53.

MERO, J.L. - $1960-$ Uses of the Gama-ray Spectrometer in Mineral Exploration Geophysics, 25: 1054-76.

MURRAY, E.G, and ADAMS, J.A.S. - 1958 Thorium, Uranium and Potassium in some Sandstones. Geochimica et Cosmochimica Acta, 13 (4): 260-69.

PARFFENORF. A. - 1967 - Aperçu Sur les Méthodes d'étude des concentrés Alluvio- naires au Laboratoire des Alluviones du B.R.G.M. Bull, 2.1967, Paris.

PARFFENOF, A., POMEROL, C. tourenq, j. - $1970-$ Les -Mineraux en Grain-Méthodes d'étude et détermination. Masson et Cie, Editeurs, Paris.

PETRIJORHN, F.J. - 1957 - Sedimentary Rocks, 2a. Ed. Harper's Geoscience Series, Nova lorque,

ROUTHIER, P. - 1963 - Les Gisements Métalliféres Geologic et Principes du $\mathrm{Re}-$ cherche. Tome I-II, Masson et Cie. Editeurs Paris.

SEIGEL, A.D. - 1967 - The induced polarization method, in Mining and Groundwate Geophysics, publ. G.S. Canada E.G. Rep. 26: 123-27.

SUGUlO, S.K. - 1973 - Introduçào à Sedimentologia. Edgard Blücher, Ed. da Universidade de São Paulo.

VIANA, D.F., GAMA, E.G., SIMŌES, I.A., MOURA, J.A., FONSECA, J.R. e ALVES, R.J. - 1971 - Revisåo estratigráfica da Bacia Recôncavo Tucano. Boletim Técnico da Petrobrás, $14(3 / 4): 157-92$, Rio de Janeiro.

VISCHER, G.S. - 1969 - Grain Size Distributions and Deposicional Process. Jour. of Sedimentary Petrology, 39 (3): 1074-106. 


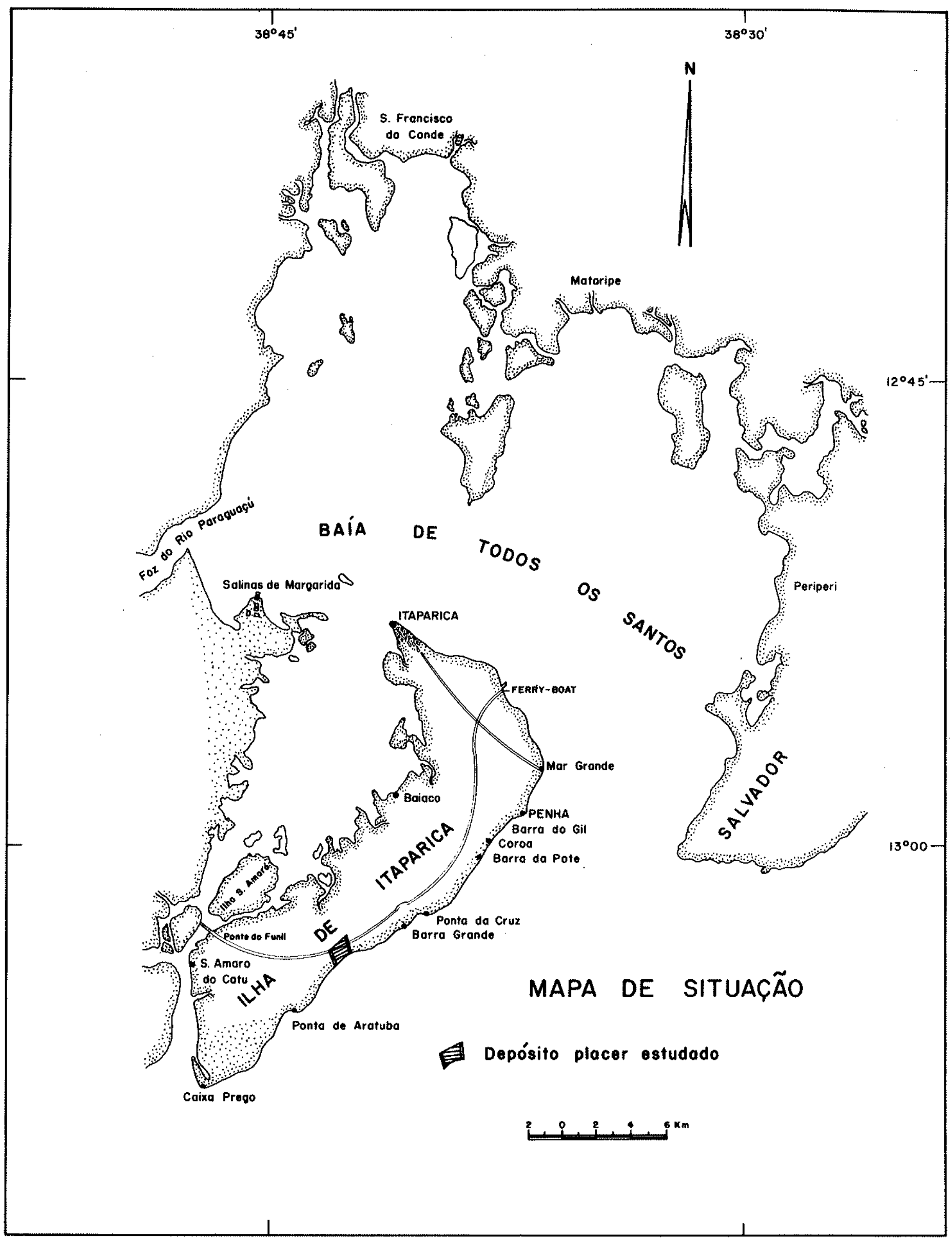



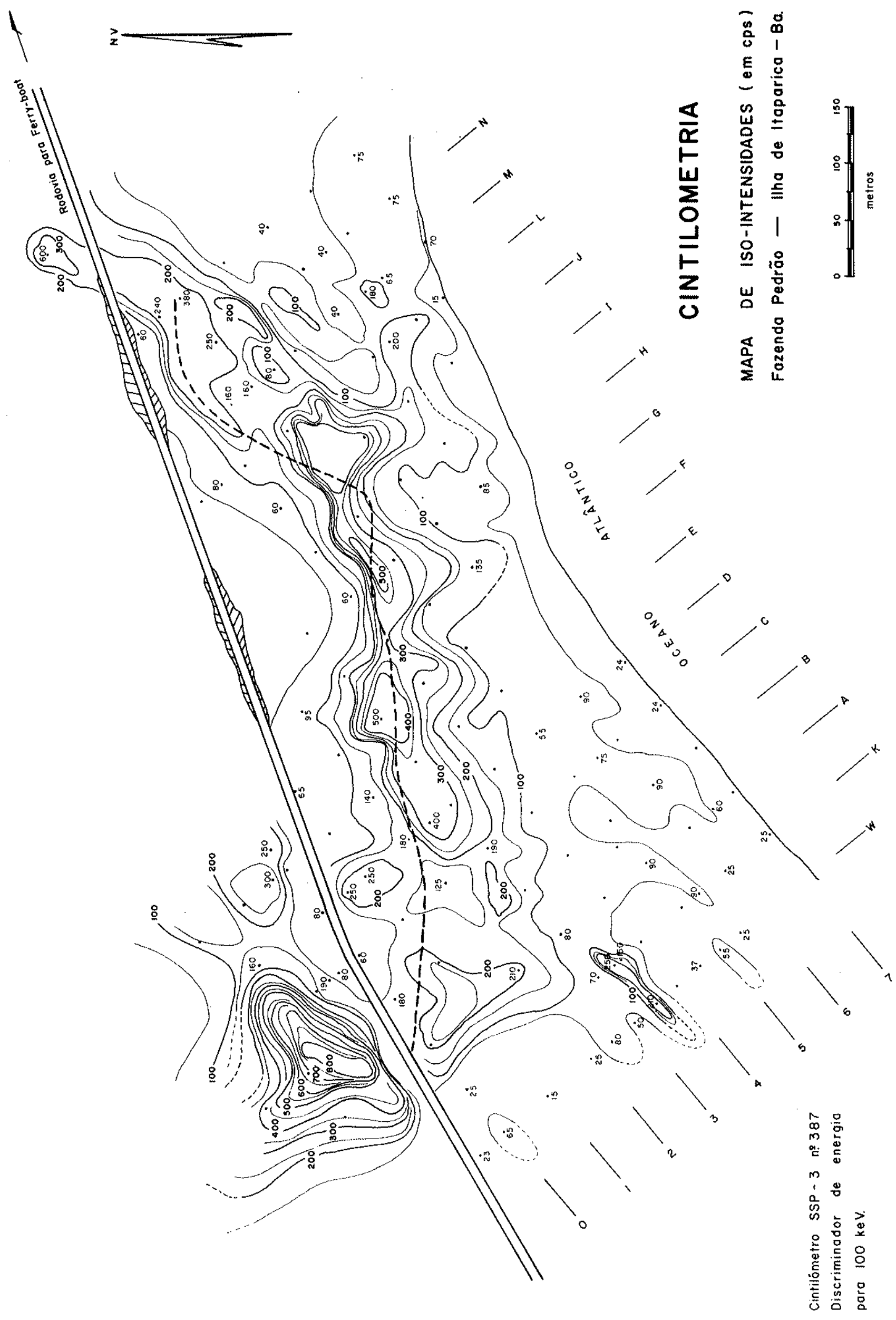


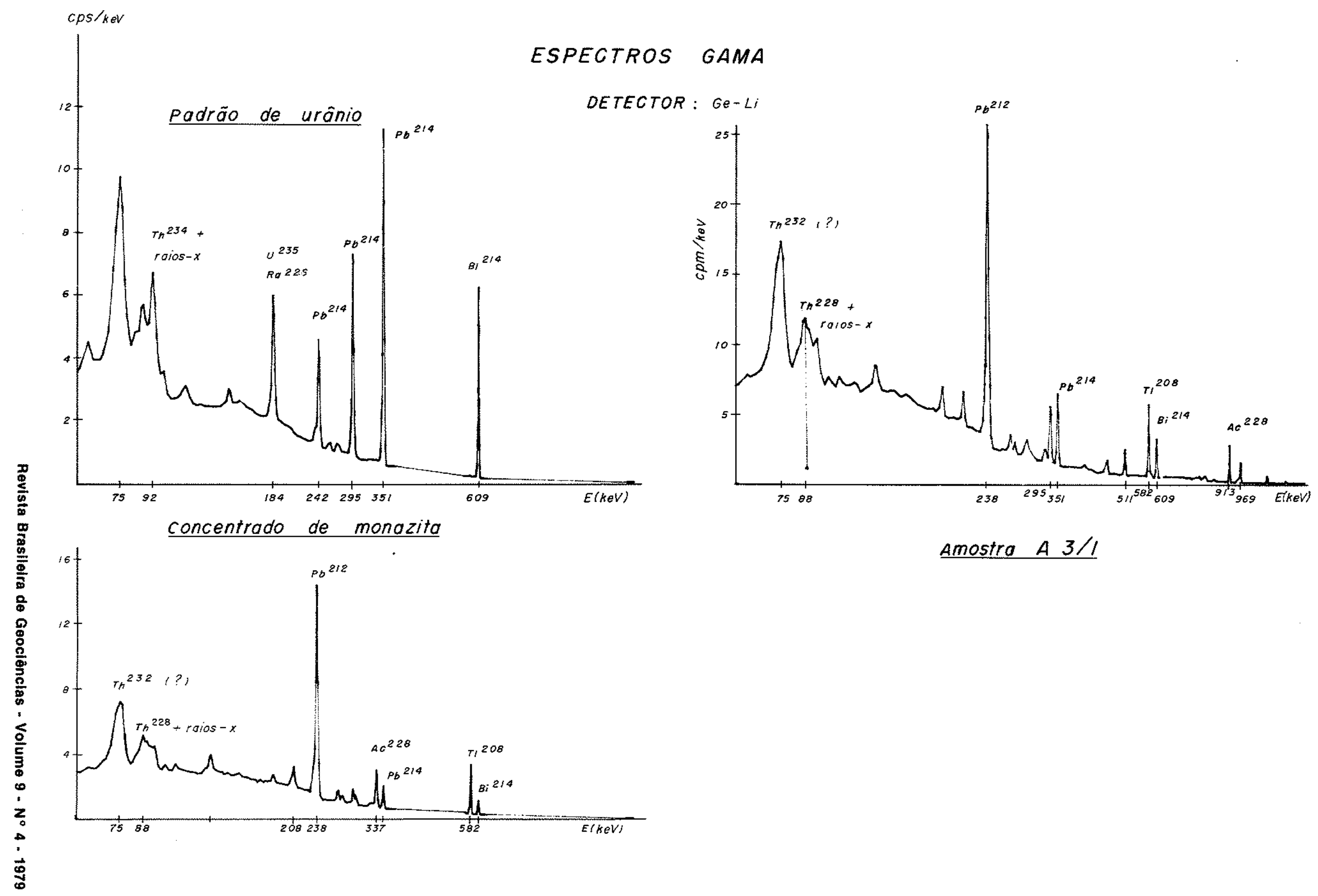




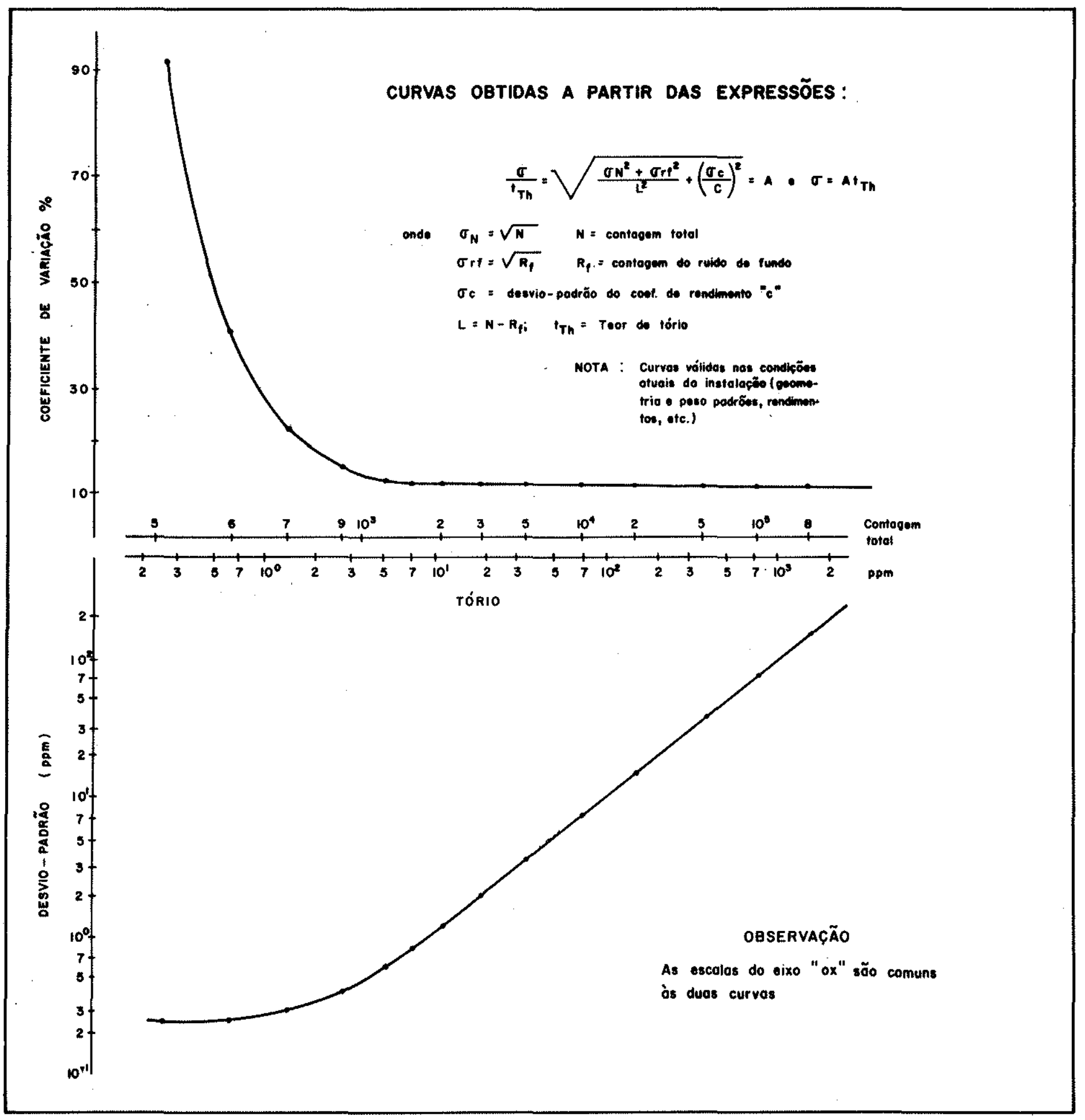


MAPA DE ISOTEORES DE TÓRIO $\left(\mathrm{ThO}_{2}\right)$ A 2,0m DE PROFUNDIDADE

Fazendo Pedrão - llha de Itoparica

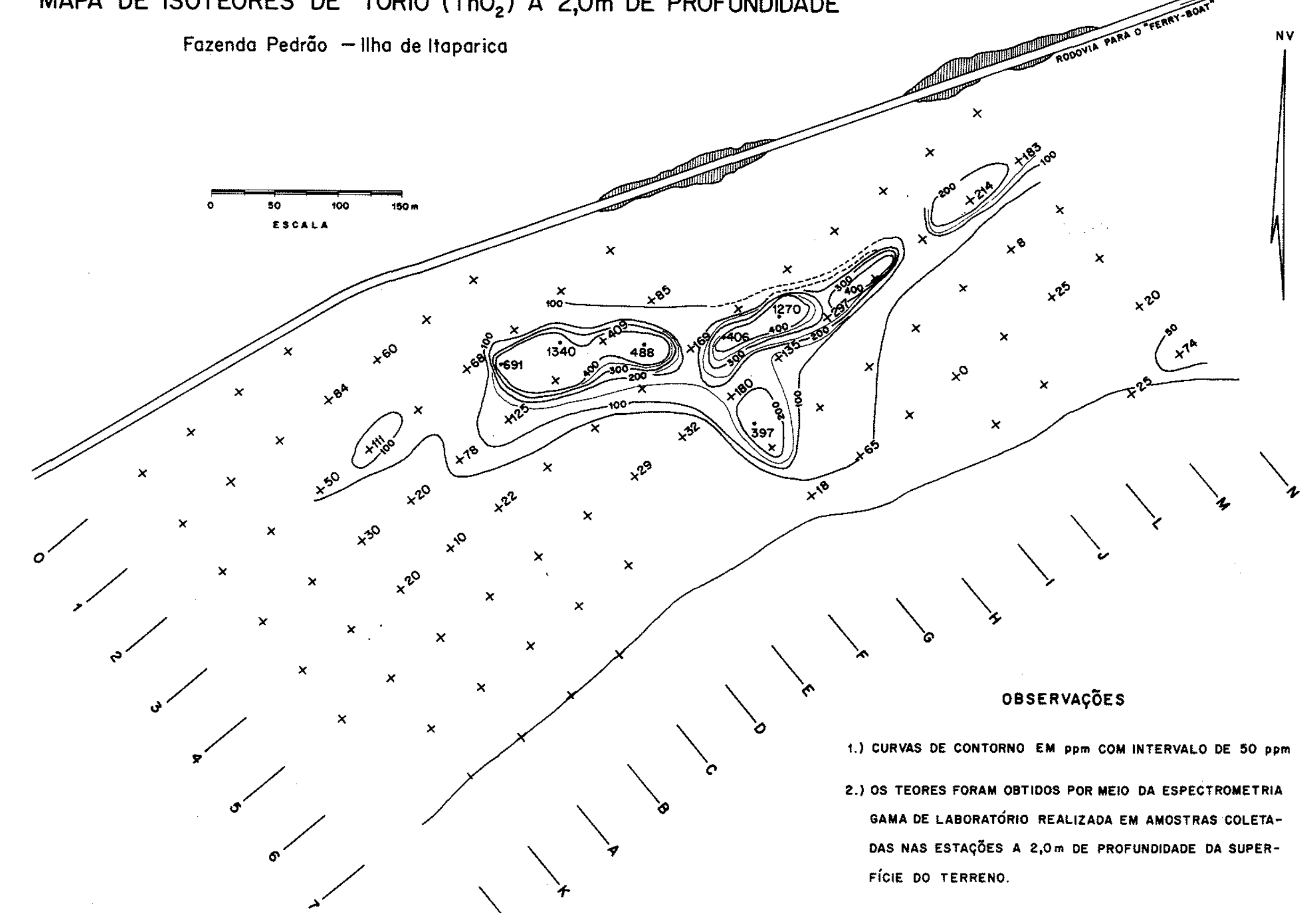




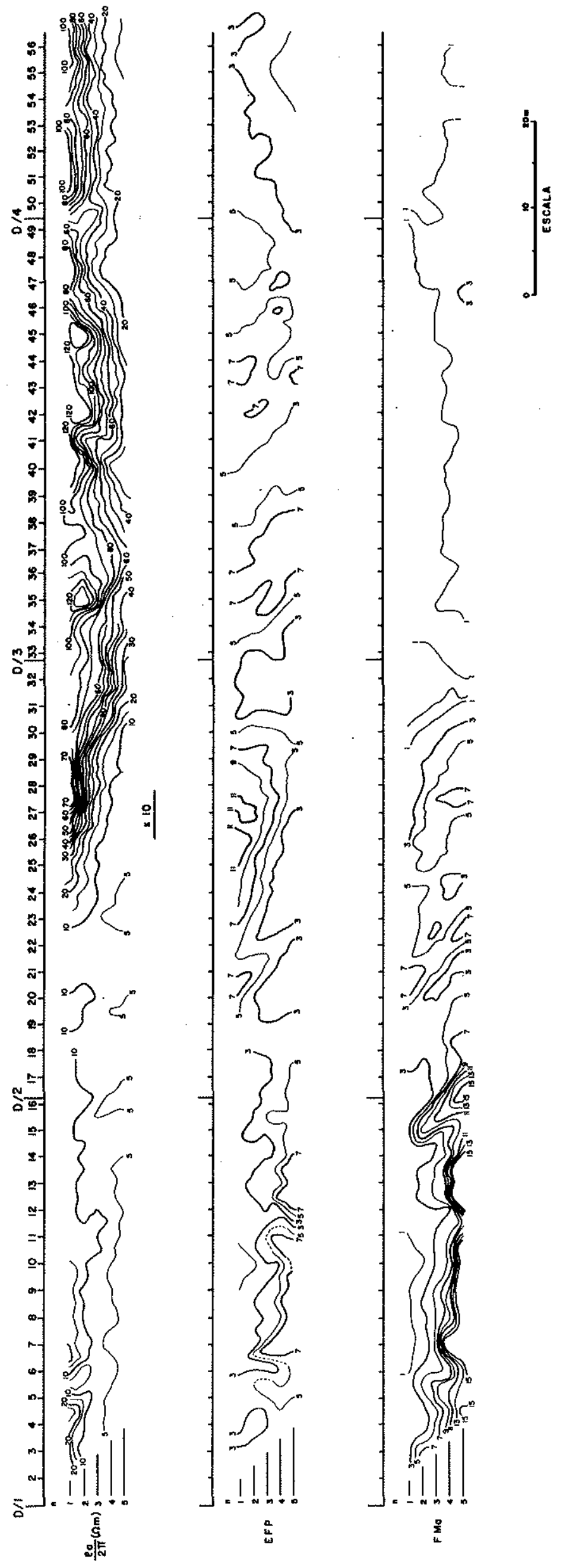




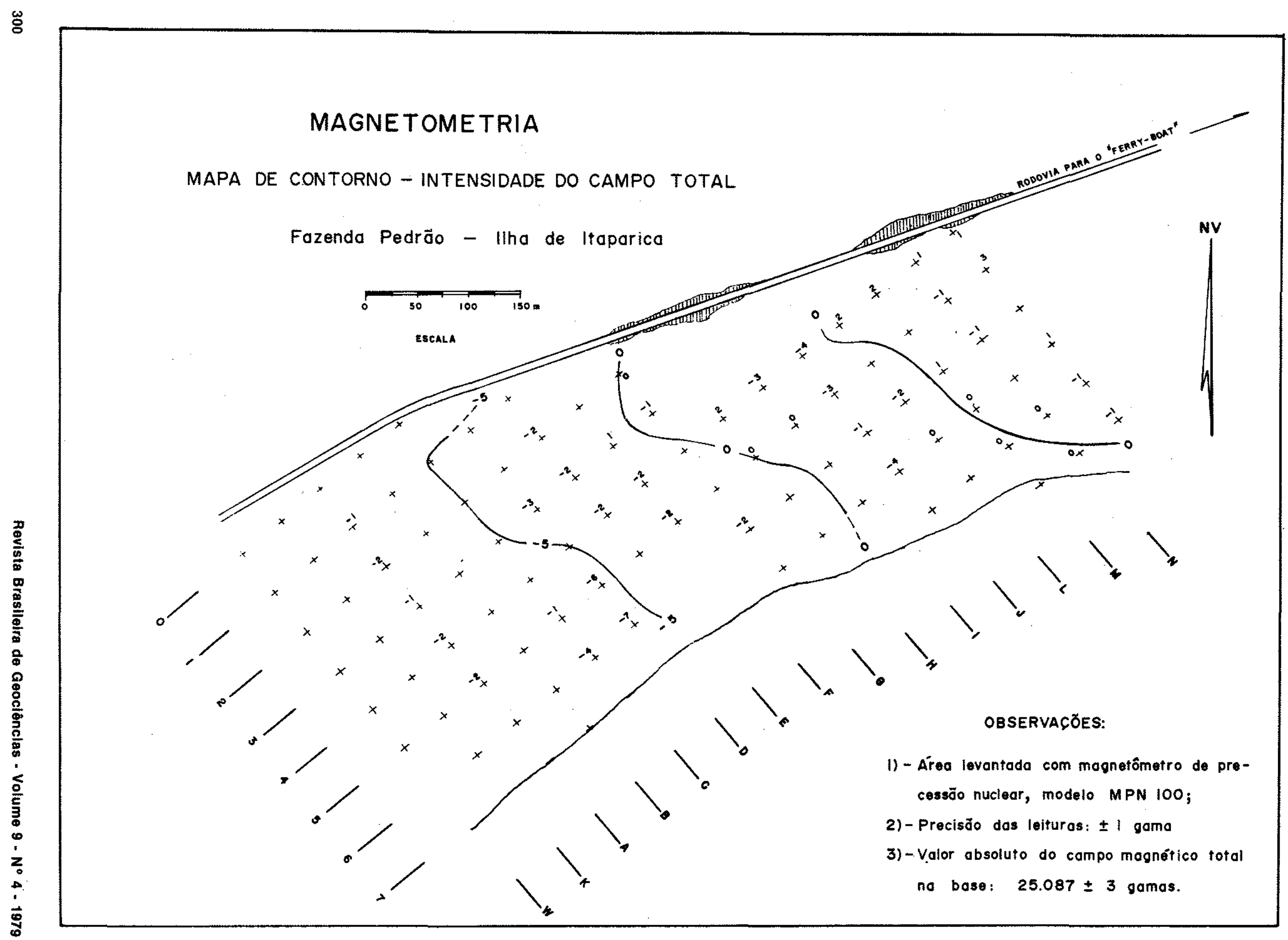




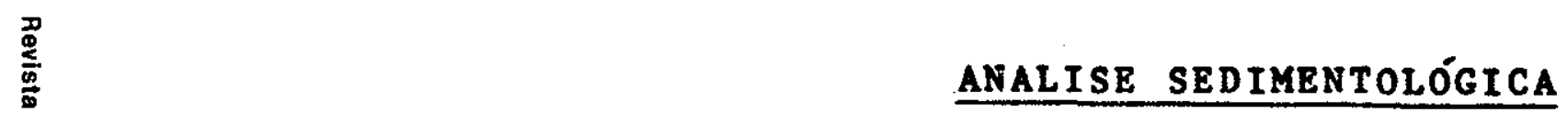

FLUXOGRAMA DE PROCESSAMENTO DAS AMOSTRAS

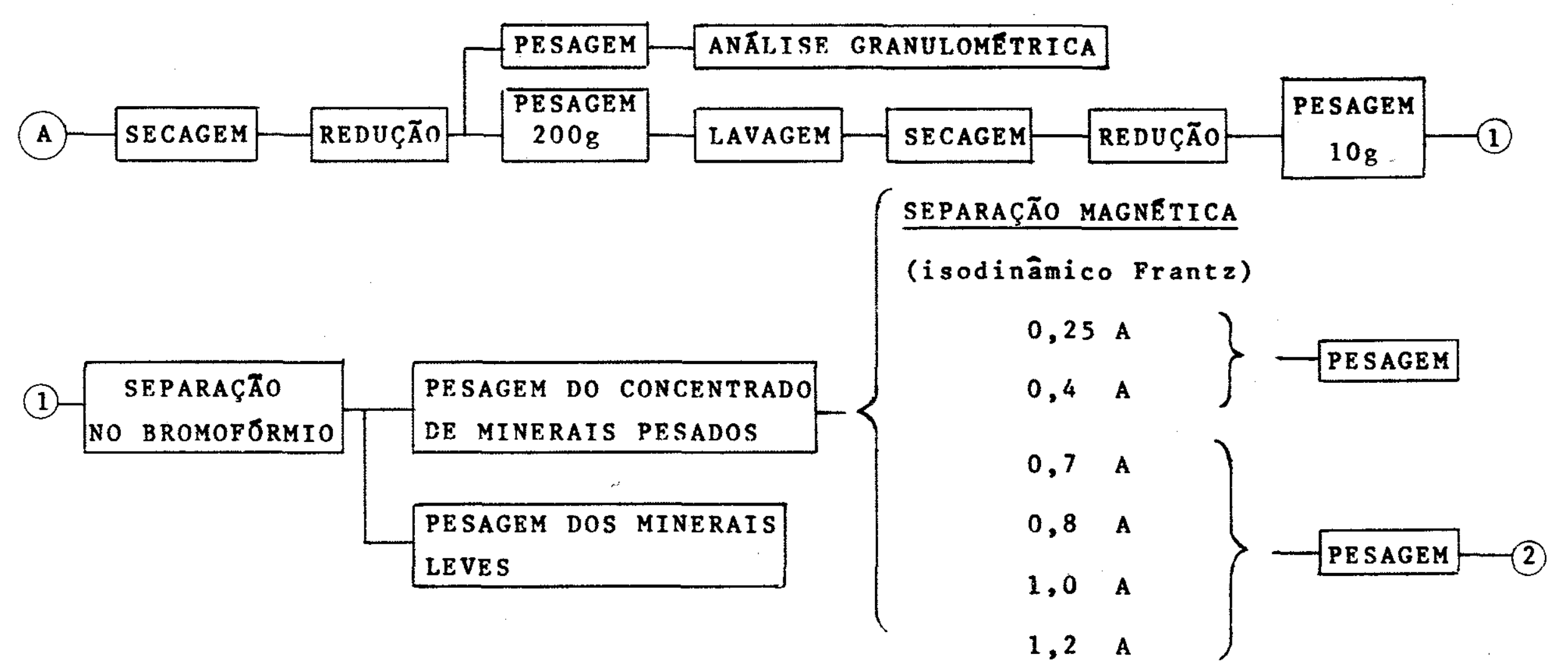

\begin{tabular}{|c|c|}
\hline MONTAGEM & ANÄLISE MICROSCÓPICA \\
\hline EM LATMINAS & (identificação e contagem) \\
\hline
\end{tabular}




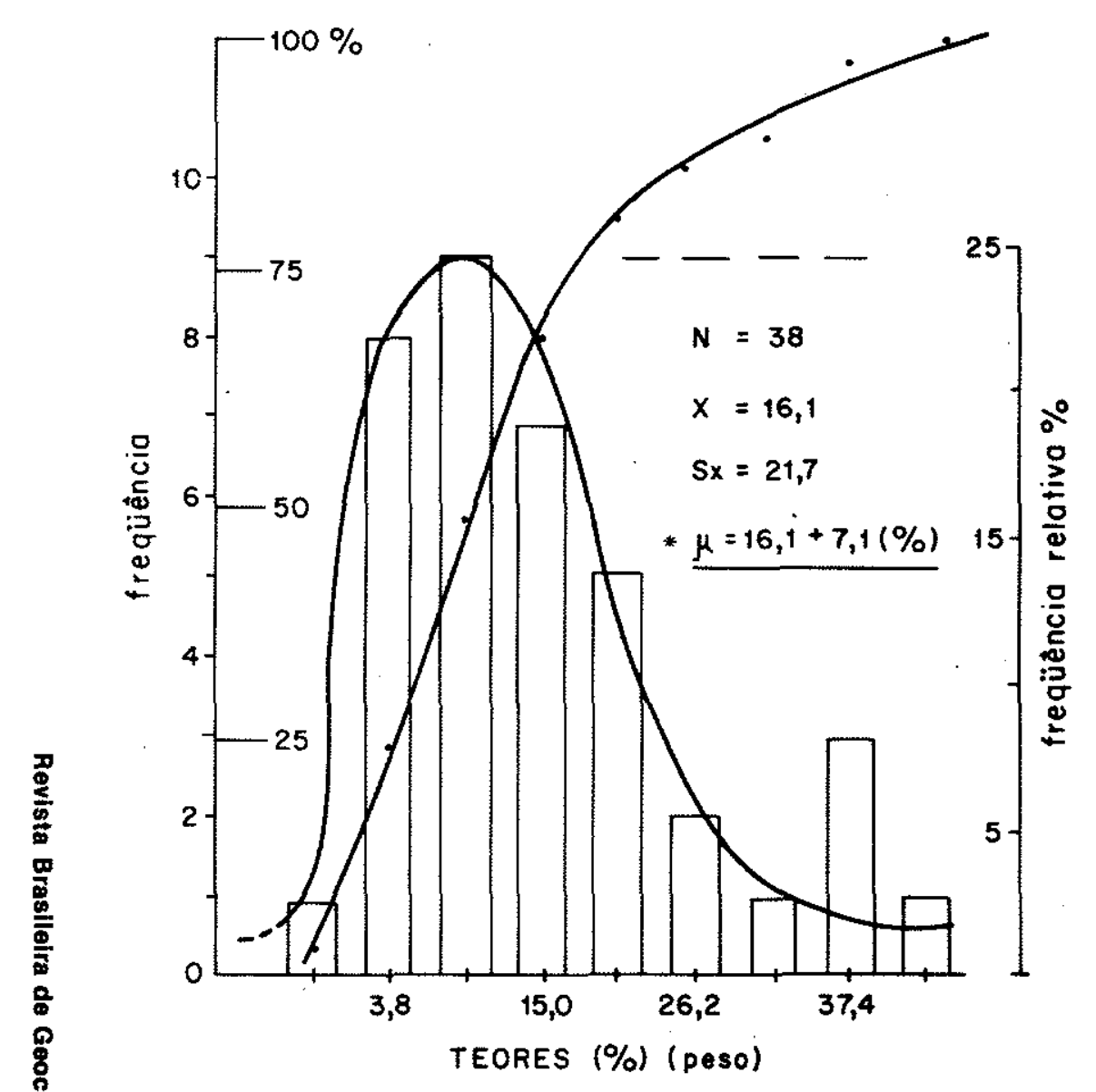

a) - Distribuição de frequêncio a 2,0 metros de profundidade

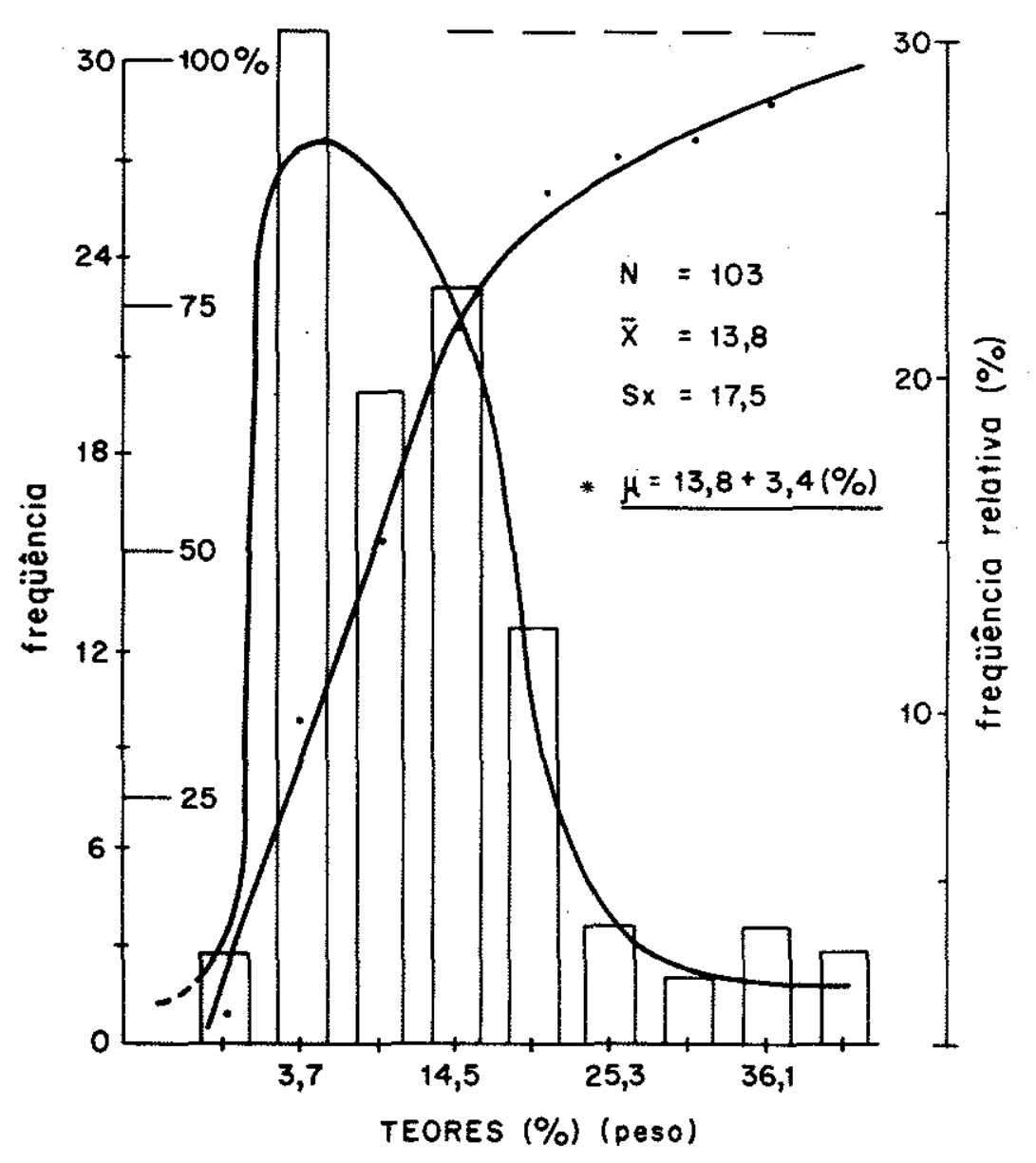

b) - Distribuição de frequência no depósito

*) Limites de confiança de $95 \%$ da média populacional 

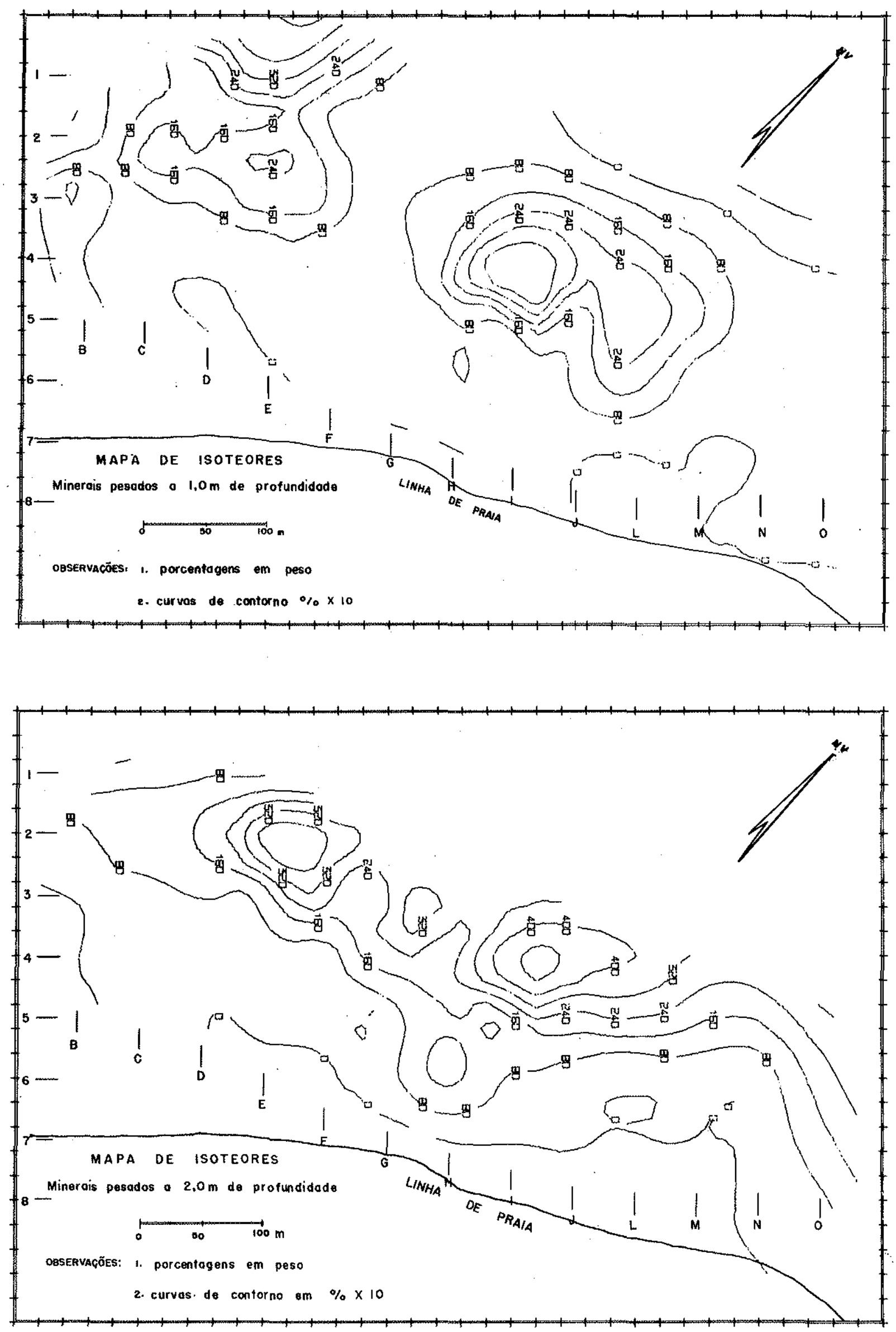


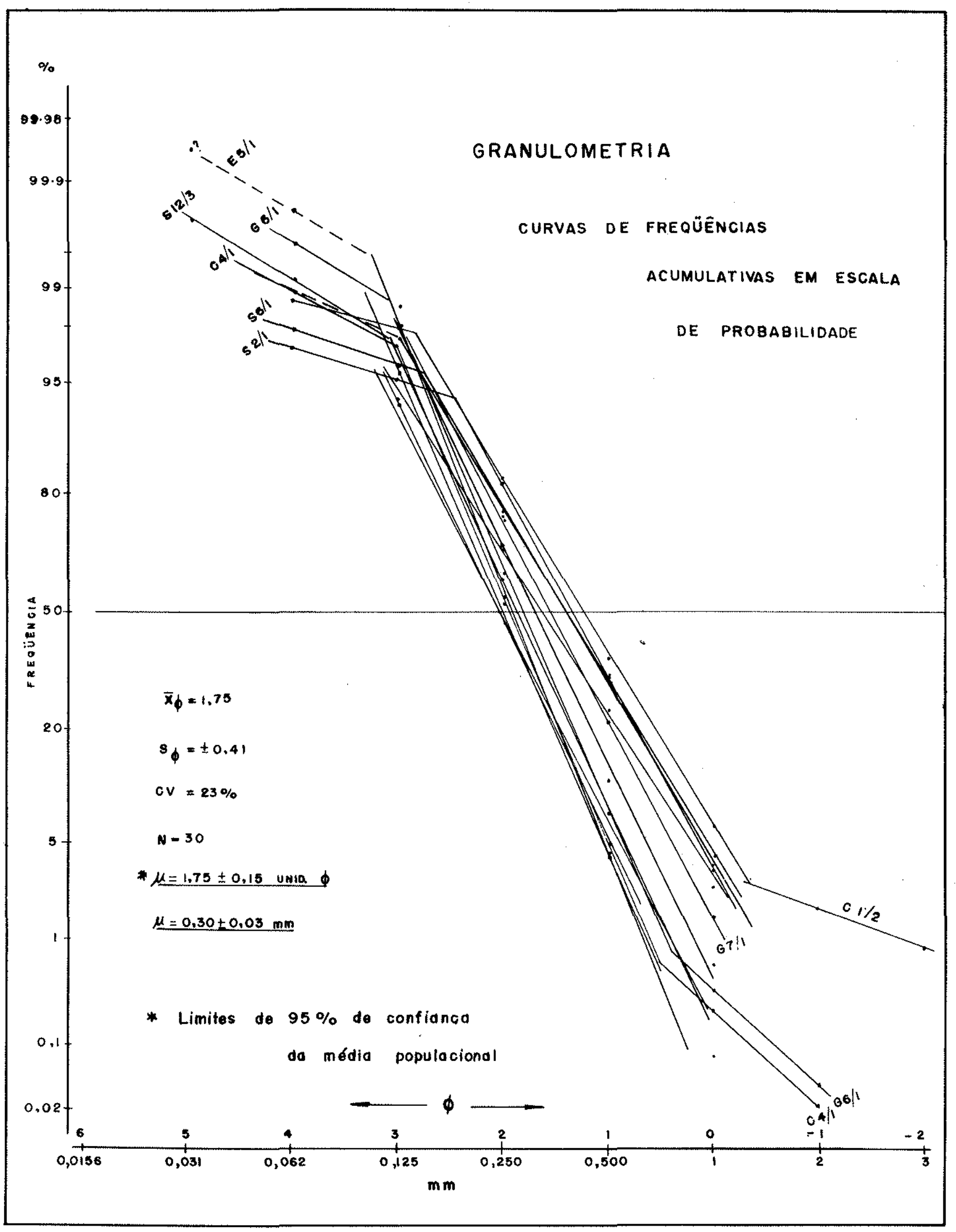




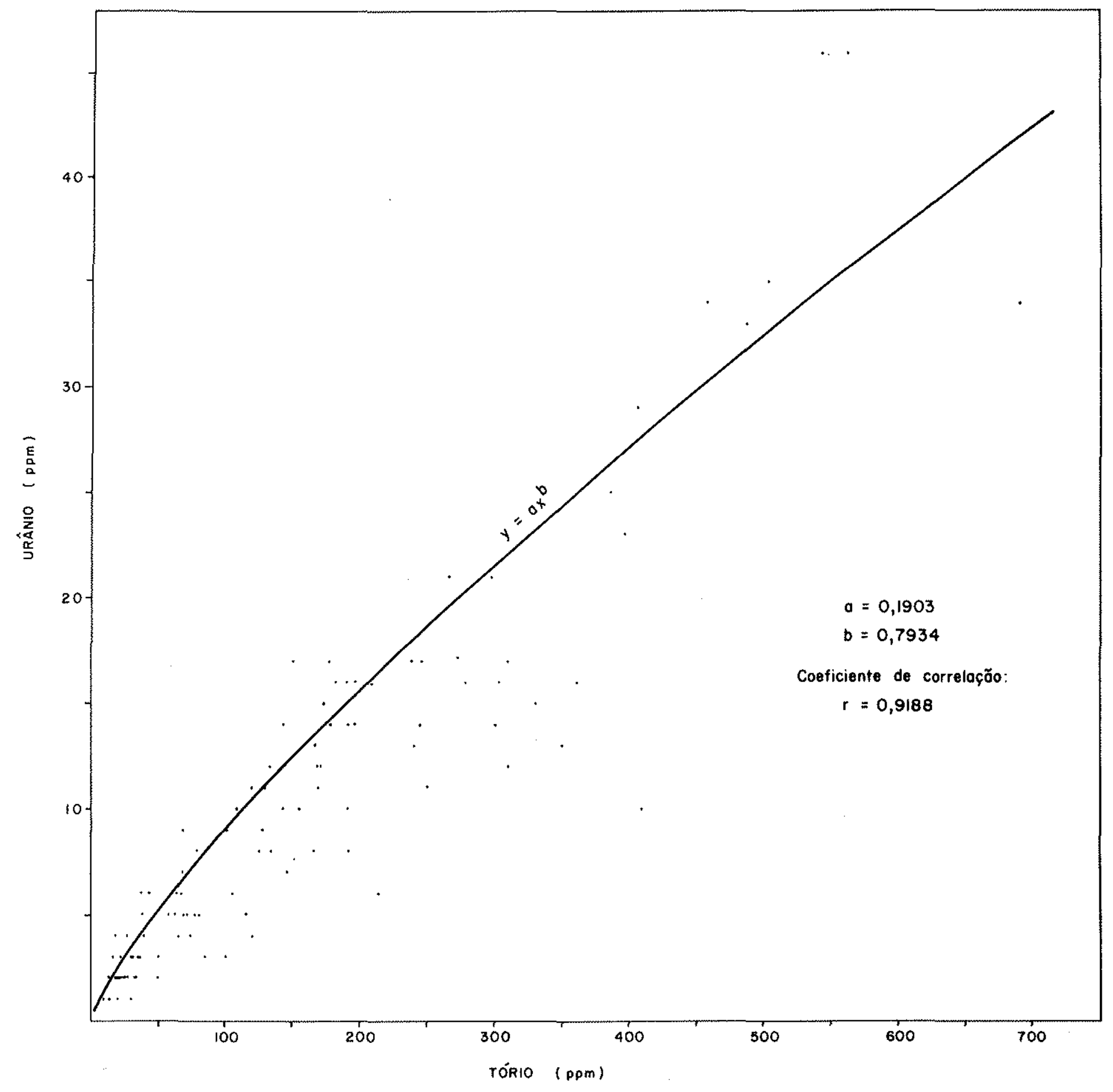




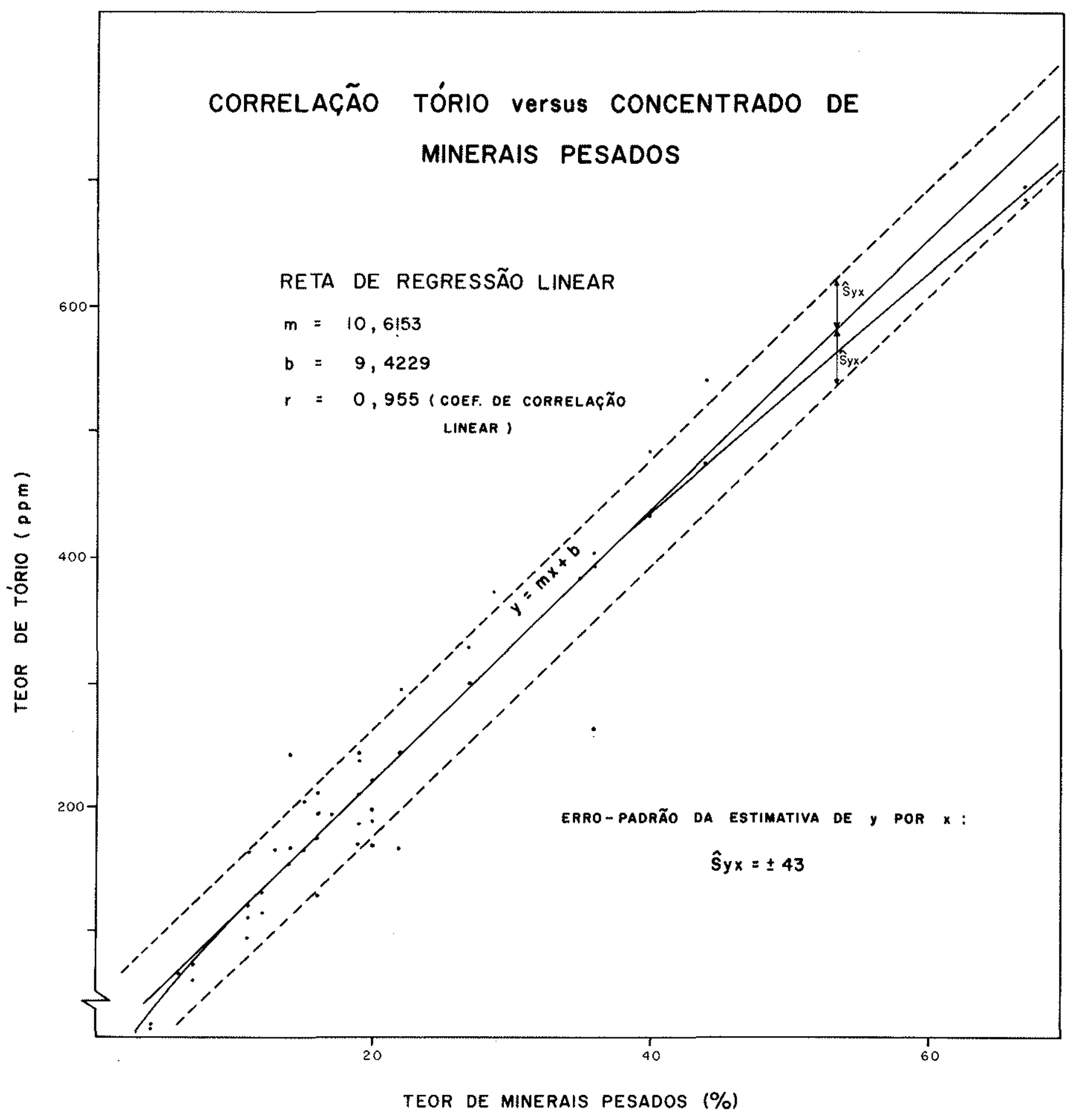




\begin{tabular}{|c|c|c|c|c|c|c|c|c|c|c|c|}
\hline \multirow{3}{*}{ AMOSTRAS } & \multicolumn{3}{|c|}{ IEORES } & \multirow{3}{*}{ AMOSTRAS } & \multicolumn{3}{|c|}{ TEORES } & \multirow{3}{*}{ AMOSTRAS } & \multicolumn{3}{|c|}{ TEORES } \\
\hline & & & & & U & Th & $x$ & & & & \\
\hline & U (ppm) & Th tppml & $K|W|$ & & $\{p \mathrm{pm}\}$ & ippmi & $\left|w^{\prime}\right|$ & & U lppml & Th (ppm) & $K|(8)|$ \\
\hline A 010 & 22 & 702 & - & G 510 & - & 7 & . & W 310 & 2 & 19 & 0,6 \\
\hline A 220 & - & 58 & - & $65 / 2$ & $\ldots$ & 180 & - & K $3 / 10$ & 2 & 22 & - \\
\hline A 212 & -. & 56 & - & G 6 6il & & 5 & - & $\times 410$ & 1 & 13 & 0,5 \\
\hline A 311 & 17 & 150 & - & 6612 & 73 & 397 & - & $S 110$ & 17 & 310 & - \\
\hline A $3 / 2$ & 3 & 30 & 00,8 & G 710 & $\therefore$ & nd & 0,7 & S 111 & 46 & 563 & 2,3 \\
\hline B 110 & 8 & 192 & 0,4 & 6712 & 2 & 18 & 0,6 & $S 1 / 2$ & - & 1276 & - \\
\hline B 111 & 3 & 100 & 0,2 & $H 5 i 0$ & 14 & 245 & 0,5 & $S 211$ & 46 & 544 & 1,5 \\
\hline $81 / 2$ & 4 & 120 & 1,2 & H $5 / 2$ & 9 & 127 & 0.7 & S 212 & 29 & 4006 & - \\
\hline B 211 & 6 & 105 & 0,3 & H 610 & - & 39 & - & $S 310$ & 16 & 361 & - \\
\hline B 212 & $\theta$ & 166 & 0,4 & H 710 & 2 & 49 & 1,1 & S $3 / 1$ & 10 & 142 & $0, B$ \\
\hline В & 7 & 67 & 0,7 & H $7 / 2$ & 4 & 65 & 0,6 & $S 3 i 2$ & 33 & $48 B$ & 0,1 \\
\hline 8410 & 4 & 17 & 0,6 & 15,2 & 21 & 297 & 0,0 & $S 3 / 3$ & 14 & 196 & 1,0 \\
\hline 841 . & 2 & 13 & 0,7 & J $5 i 0$ & 17 & 238 & 0,5 & $S 3 / 2$ & 34 & 458 & 0,0 \\
\hline C 110 & 9 & 68 & 0,8 & J & 35 & 5014 & 0,5 & S 411 & 5 & 57 & 0.4 \\
\hline C $1 / 1$ & 7 & 146 & 1,0 & J 512 & - & - & - & $S 4 i 2$ & 5 & 62 & 0,6 \\
\hline C 2210 & 5 & 48 & 0,8 & $J 6 i 0$ & 5 & 70 & 0.9 & S $4 / 4$ & 10 & 108 & 0,3 \\
\hline C. 211 & 5 & 80 & 1,3 & 161 & 3 & 23 & 1,0 & S 510 & 8 & 135 & 0,4 \\
\hline C 310 & 9 & 100 & 0,6 & $\mathrm{~J} 612$ & - & nd & - & $S 511$ & 14 & 301 & 0,3 \\
\hline C $3 / 2$ & 8 & 78 & 0,9 & 3710 & 6 & 67 & 1,1 & $S 512$ & 34 & 691 & - \\
\hline C 410 & 2 & 26 & 1,1 & d & & 20 & - & $S 5 / 3$ & 5 & 115. & 0,8 \\
\hline C 411 & 3 & 21 & 0,9 & $57 / 2$ & - & nd & - & $S 661$ & 15 & 331 & 0,3 \\
\hline C $4 / 2$ & 3 & 21 & 0,8 & 140 & 1 & 29 & - & $S 71$ & 16 & 278 & 0,3 \\
\hline D 110 & 10 & 155 & 0,3 & $4: 1$ & 3 & 50 & 0,1 & S 811 & 5 & 57 & 0,6 \\
\hline D 111 & 10 & 190 & 0,4 & $1 ; 1$ & - & 171 & - & $S 8 / 3$ & 9 & 99 & 0,6 \\
\hline D 112 & 5 & 68 & 0,8 & L $6 i 1$ & 3 & 34 & 1,6 & S 10i0 & 3 & 30 & 0,4 \\
\hline 0.310 & 11 & 250 & 0,3 & 1710 & - & nd & - & $S 10,13$ & 4 & 26 & - \\
\hline D 311 & 12 & 310 & 0,4 & 1711 & - & nd & - & S 1110 & 16 & 190 & 0,1 \\
\hline 0312 & 8 & 125 & 0,7 & 1810 & - & 4 & - & S 1111 & 14 & 143 & 0,4 \\
\hline 0411 & 4 & 39 & 0,6 & L 811 & - & y & - & $S 1112$ & 15 & 173 & 0,3 \\
\hline 0511 & - & 3 & 0,8 & M 5ilo & - & 1 & - & $S 1113$ & 25 & 386 & 0,0 \\
\hline E 310 & 13 & 240 & 0,4 & $M 511$ & 6 & 43 & - & $S 1210$ & 12 & 168 & 0,3 \\
\hline E $3 / 1$ & 34 & 145 & 2,2 & M 512 & 6 & 214 & 0,3 & S 1211 & 12 & 171 & 0,4 \\
\hline E $3 / 2$ & 48 & 1300 & $-\overline{0}$ & $M 610$ & $\cdots$ & no & " & S 1213 & 16 & 303 & 1,3 \\
\hline E $4 / 1$ & 6 & 36 & 0,6 & $M 612$ & 1.0 & 8 & 0,3 & S 1212 & 11 & 119 & - \\
\hline E SiO & 2 & 33 & 2,0 & $M 710$ & - & nd & & $S$ 13il & 14 & 178 & 0,2 \\
\hline E 512 & 3 & 29 & 2,2 & $M 712$ & 3 & 25 & 0,1 & $S 13^{x} 1$ & 16 & 208 & 0,3 \\
\hline f 211 & 3 & 15 & 1,0 & $M$ Bio & - & 7 & 0,2 & $S 13 i 2$ & 11 & 129 & 0,6 \\
\hline$f 30$ & 13 & 350 & 0,2 & M 9i0 & - & nơ & - & 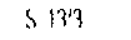 & 14 & 192 & 0,3 \\
\hline$f 31$ & 2 & 28 & 0,1 & M $9 / 1$ & - & 7 & 0,1 & S 1:41 & 14 & 173 & 0,1 \\
\hline F 312 & 10 & 409 & 0,9 & $M 912$ & - & 3 & 0,1 & $S 14 / 2$ & 12 & 133 & 0,5 \\
\hline $\mathrm{F} 411$ & - & 31 & - & $N 410$ & 6 & 63 & 0,1 & $S 143$ & 21 & 266 & 0,1 \\
\hline F 51 & 2 & 24 & 1,3 & $\mathrm{~N}$ bilo & - & 2 & - & S 1512 & 16 & $\$ 96$ & 0,2 \\
\hline$F 512$ & 2 & 32 & 0,7 & N 511 & 17 & 177 & - & $S 1513$ & 17 & 246 & 0,0 \\
\hline G 111 & 1 & 19 & 1,7 & $N 5 / 2$ & 16 & 182 & $-\cdot$ & S 1511 & 13 & 166 & - \\
\hline 6210 & - & nd & - & $\mathrm{N} 770$ & - & nd & - & $S 1410$ & 5 & 37 & 0,2 \\
\hline $62 n$ & 2 & 37 & 2,0 & $N M$ & 4 & 26 &. & S $15 / 0$ & 11 & 169 & 0,1 \\
\hline G 310 & - & 42 & - & N 91 & - & 2 & - & $S 913$ & 3 & 36 & 0,4 \\
\hline G 311 & - & 193 & - & N 912 & 4 & 74 & 0,6 & $\mathrm{~S} 9 / 2$ & 2 & 18 & 0,9 \\
\hline $63 / 2$ & 3 & 85 & 1,1 & 0511 & 8 & 135 & 0,9 & S 101 & 3 & 31 & 0,6 \\
\hline G 40 & - & 201 & - & 0611 & 2 & 32 & 1,3 & $S 19 / 2$ & 2 & 20 & 0,7 \\
\hline G 412 & - & 167 & - & W 410 & 1 & 13 & 0,7 & $\mathrm{~S} 220$ & 5 & $n 7$ & 0.6 \\
\hline
\end{tabular}




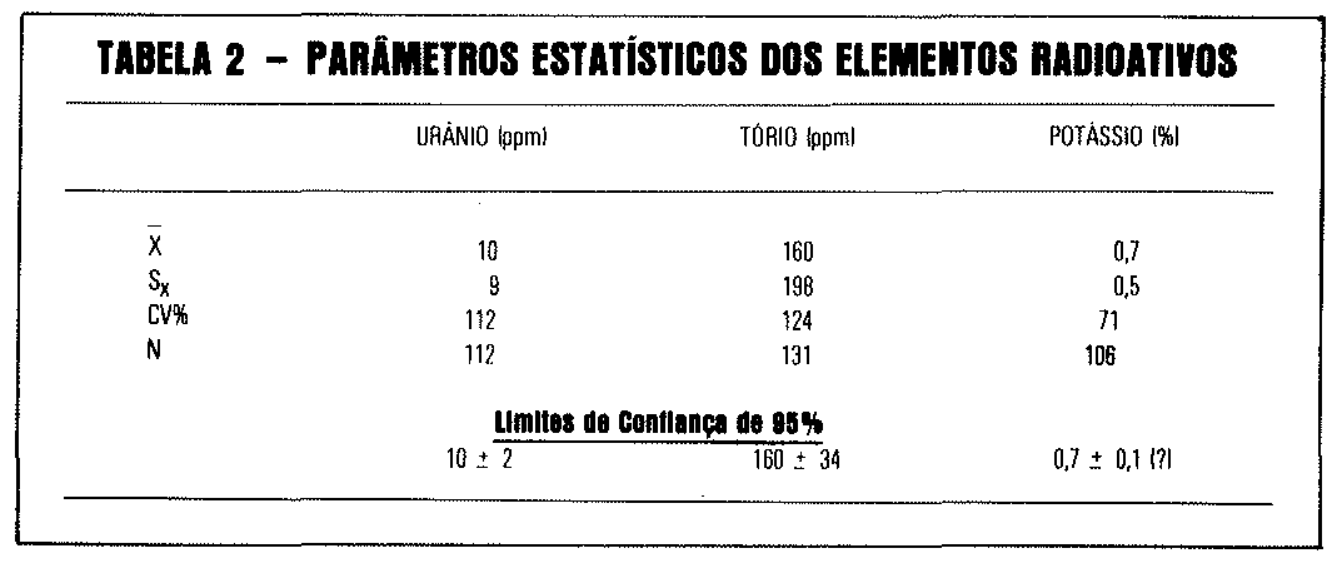

\begin{tabular}{|lcc|}
\hline \multicolumn{4}{c|}{ TABELA 3 - MUNERAIS ÚTEIS DA JAZZMA } \\
\hline ESPECIE & TEOR MEDIO $(\%)$ & ERRO PROVAVEL \\
\hline IImanita & 58 & \pm 2 \\
Monzzita & 4 & \pm 1 \\
Zirconita & 5 & \pm 2 \\
Rutilo & 0,9 & $\pm 0,2$ \\
\hline
\end{tabular}

\section{tabela 4 - Parámetros mÉdios anosthals do SEDIMEATo}

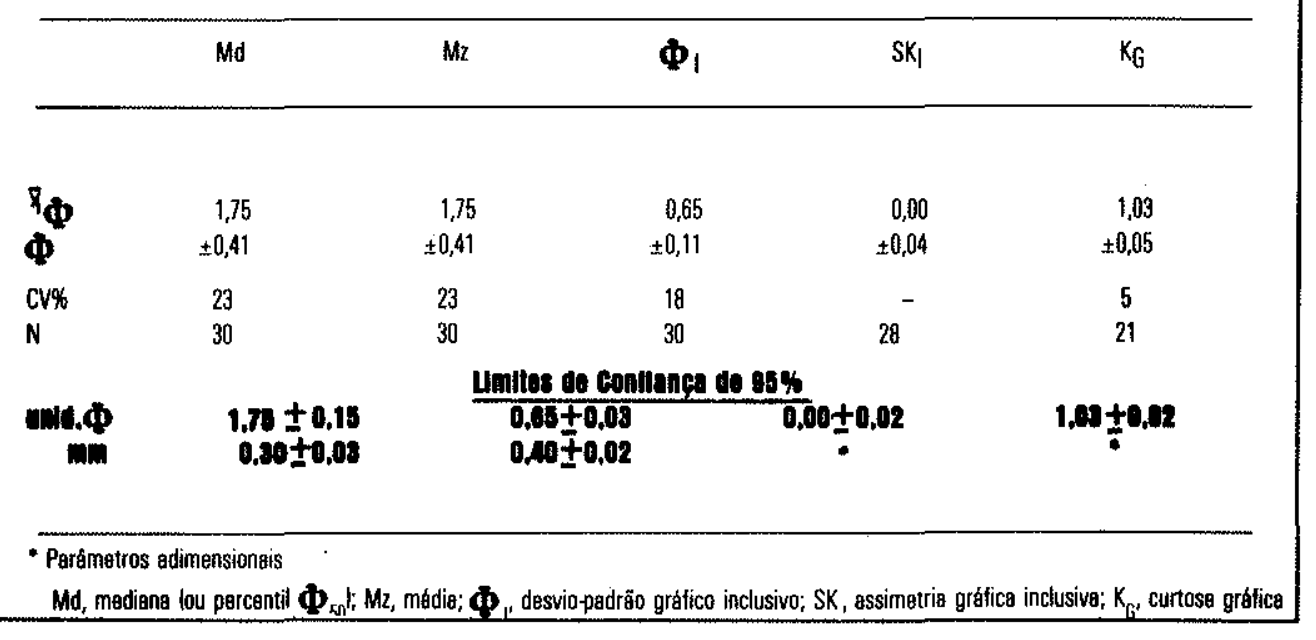

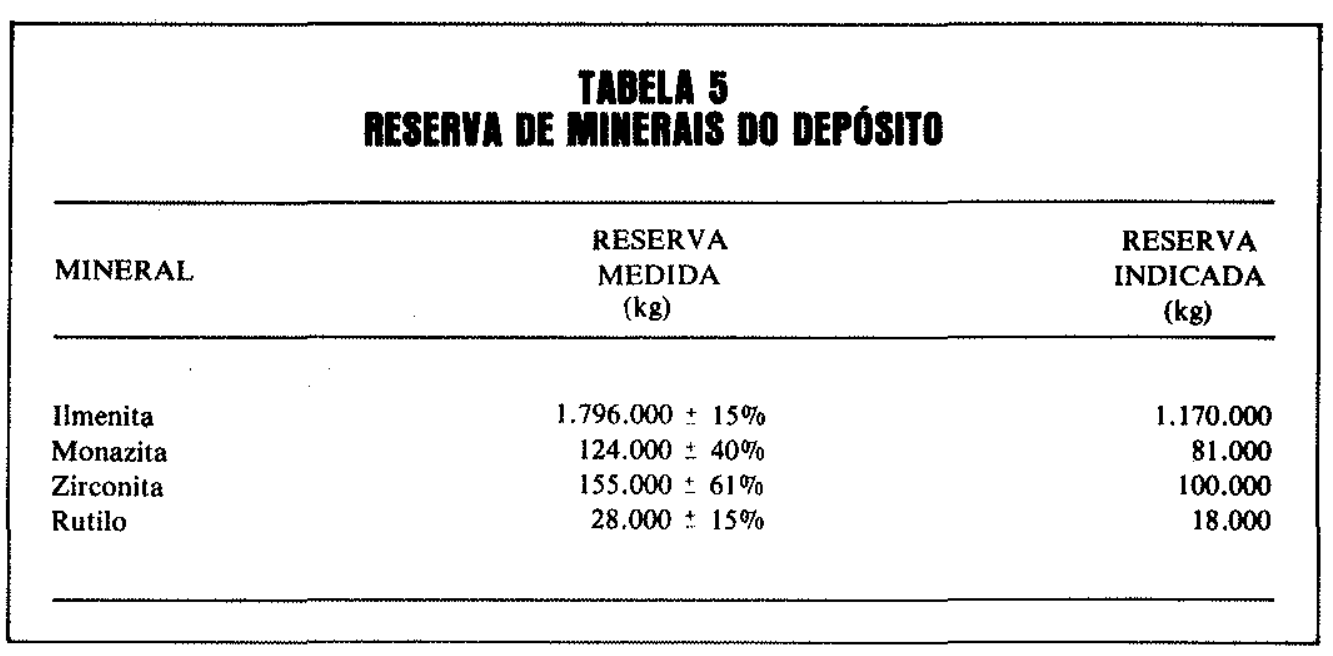

